\title{
PERFIL DOS COMPONENTES VOLÁTEIS PRODUZIDOS PELO FUNGO FITOPATÓGENO Albonectria rigidiuscula EM DIFERENTES CONDIÇÕES DE CULTIVO
}

\author{
Francisco C. Oliveira ${ }^{a}$, Francisco G. Barbosa ${ }^{\mathrm{a}, *}$, Jair Mafezoli ${ }^{\mathrm{a}}$, Maria da C. F. de Oliveira ${ }^{\mathrm{a}}$, Francisco J. T. Gonçalves ${ }^{\mathrm{b}}$ e \\ Francisco C. O. Freire ${ }^{\text {b }}$ \\ aDepartamento de Química Orgânica e Inorgânica, Universidade Federal do Ceará, 60455-760 Fortaleza - CE, Brasil \\ ${ }^{b}$ Embrapa Agroindústria Tropical, Rua Dra. Sara Mesquita, 2270, Planalto do Pici, 60511-110 Fortaleza - CE, Brasil
}

Recebido em 15/12/2016; aceito em 10/04/2017; publicado na web em 13/06/2017

\begin{abstract}
VOLATILE COMPONENTS PROFILE PRODUCED BY THE PHYTOPATHOGENIC FUNGUS Albonectria rigidiuscula IN DIFFERENT CONDITIONS CULTURE. The VOCs produced by the Albonectria rigidiuscula fungus in different conditions were obtained by headspace-solid phase microextraction (HS-SPME) and analyzed by gas chromatography-mass spectrometry (GC-MS). Fourty-four VOCs were identified in different culture media and incubation periods. The highest production of VOCs occurred in solid rice medium and 14 days of incubation. The compounds 3-methylbutan-1-ol, 2-methylbutan-1-ol, $\gamma$-muurolene and nerolidol acetate were produced by A. rigidiuscula in all culture conditions. $\gamma$-Muurolene was identified as the major compound $(40.78 \%, 26.24 \%$ and $27.04 \%$ ) in PD medium and it was suggested as a chemical marker for this fungus. The use of multivariate data analysis (PCA) and (HCA) allowed the discrimination of the volatile chemical profiles according to the culture medium.
\end{abstract}

Keywords: Albonectria rigidiuscula; VOCs; HS-SPME; multivariate analysis.

\section{INTRODUÇÃO}

Albonectria rigidiuscula (Berk. \& Br.) Ross. \& Sam., sin. Calonectria rigidiuscula e Nectria rigidiuscula (Nectriaceae) é um fungo fitopatógeno que tem como anamorfo o fungo Fusarium decemcellulare.$^{1}$ A espécie $A$. rigidiuscula é comum em países tropicais, sendo descrita também na China. ${ }^{2-4}$ No Brasil esta espécie é causadora da cancrose da pinha (Annona squamosa L.) e compromete o cultivo dessa cultura no cerrado de Goiás, Minas Gerais e Distrito Federal. Neste caso, a infecção da planta é iniciada por conídios ou esporos do anamorfo $F$. decemcellulare ou por ascósporos de $A$. rigidiuscula. Após o estabelecimento da fitopatologia e formação do cancro, a resposta desencadeada pela planta infectada faz com que o anamorfo F. decemcellulare, em estágio envelhecido, passe a produzir a sua fase teleomorfa ou perfeita, transformando-se em A. rigidiuscula. ${ }^{5}$

$\mathrm{O}$ anamorfo $F$. decemcellulare também está relacionado com importantes fitopatologias, tais como morte de ponteiras, cancrose, galhas, podridão dos frutos, cancro-do-ramo e superbrotamento de plantas das famílias Anacardiaceae, Annonaceae, Sterculiaceae, Malvaceae, Apocynaceae, Euphorbiaceae, Meliaceae, Moraceae e Myrtaceae. ${ }^{5}$ Exemplo de dano causado na agricultura foi relatado por Qi et al., no qual durante os anos de 2009 e 2011 uma doença causada por $F$. decemcellulare comprometeu significativamente o cultivo de manga (Mangifera indica) na China. ${ }^{6}$ A partir do cultivo de $A$. rigidiuscula em meio fermentativo de arroz foram isolados quatro derivados de pirrolidinona com potencial citotóxico. ${ }^{3}$ Para o anamorfo $F$. decemcellulare foram identificados 10 pigmentos naftoquinônicos, sendo sua biossíntese influenciada diretamente pelas condições de cultivo. ${ }^{7}$ Não há relatos de estudos relacionados à produção de compostos orgânicos voláteis (COVs) por A. rigidiuscula ou seu anamorfo.

Em nosso grupo de pesquisa temos investigado a produção de COVs como uma ferramenta auxiliar na discriminação de fungos da família Botryosphaeriaceae. Nos estudos são combinadas técnicas de microextração em fase sólida por headspace (HS-SPME), análise por

*e-mail: fgerhar@gmail.com cromatografia gasosa acoplada à espectrometria de massas (CG-EM) e análise multivariada de dados (PCA e HCA). ${ }^{8}$

Sabendo-se que a produção de COVs por espécies fúngicas ocorre através de mecanismos diversificados em função das diferentes fontes de carbono ou nitrogênio, ${ }^{9}$ neste trabalho, descreve-se a investigação do perfil de COVs produzidos pelo fungo fitopatógeno $A$. rigidiuscula cultivado em quatro meios de cultura diferentes e em três períodos de incubação; usando a HS-SPME como técnica de extração, a CG-EM como técnica de análise e a PCA/HCA como ferramenta quimiométrica para tratamento de dados.

\section{EXPERIMENTAL}

\section{Obtenção e identificação do fungo}

Uma cepa do fungo A. rigidiuscula foi isolada a partir de ramos de Psidium guajava com sintomas de seca descendente, coletada no bioma Caatinga, Crato-CE (S 07¹3'38”; W 39²6'20”), Brasil e encontra-se depositada no laboratório de Fitopatologia da Embrapa Agroindústria Tropical - CNPAT sob a supervisão do Dr. Francisco das Chagas Oliveira Freire.

A identificação do fungo se deu através de biologia molecular, com DNA extraído a partir do micélio de uma cepa, utilizando kit de isolamento UltraClean Microbial DNA da Mo-Bio laboratories. Fragmentos contendo o gene do RNA ribosomal 26S, grande subunidade D1 e D2 região (LSU) foram amplificados utilizando os primers LR0R (ACCCGCTGAACTTAAGC) e LR5 (TCCTGAGGGAAACTTCG). Fragmentos contendo o espaçador transcrito interno 1 e 2 e o gene 5.8.S (ITS) foram amplificados utilizando primers LS266 (GCATTCCCAAACAACTCGACTC) e V9G (TTACGTCCCTTTGTA). Fragmentos contendo o fragmento parcial do gene betatubulina (BT) foram amplificados utilizando primers BT2a (GGTAACCAAATCGGTGCTGCTTTC) e BT2b (ACCCTCAGTGTAGTGACCCTTGGC). Fragmentos contendo o fragmento parcial do gene de actina (ACT) foram amplificados utilizando primers ACT-512F (ATGTGCAAGGCCGGTTTCGC) e ACT-783R (TACGAGTCCTTCTGGCCCAT). Fragmentos contendo 
o Translocation Elongation Factor 1 alfa (TEF) foram amplificados utilizando primers EF1-728F (CATCGAGAAGTTCGAGAAGG) e EF2 (AACTTGCAGGCAATGTGG). Os fragmentos foram sequenciados com o kit de sequenciamento ABI Prim ${ }^{\circledR}$ Big DyeTM Terminator v.3.0 ready Reaction Cycle. As amostras foram analisadas em analisador genético ABI PRISM 3700 Genetic Analyzer e os contigs foram montados utilizando as sequências de avanço e retrocesso com o programa SeqMan da LaserGene package. Uma análise multigênica foi realizada comparando as sequências no GenBank, on http://www.cbs.knaw.nl/ e na base de dados interna da CBS com as espécies mais recentes.

\section{Meios de cultura e materiais}

Caldo de batata dextrose (BD) foi adquirido da Himedia ${ }^{\circledR}$ (Mumbai, India) e preparado de acordo com instruções do fabricante $\left(24,0 \mathrm{~g} \mathrm{~L}^{-1}, \mathrm{pH} 5,1 \pm 0,2\right)$. O meio peptona foi obtido da Sigma-Aldrich ${ }^{\circledR}$ (St. Louis, USA). O meio semi-sólido batata dextrose agar (BDA) foi obtido da Himedia ${ }^{\circledR}$ (Mumbai, India) e preparado de acordo com instruções do fabricante. O meio sólido foi preparado com arroz "Uncle Bens" $(10 \mathrm{~g})$ adicionado em um frasco de vidro de $40 \mathrm{~mL}$, juntamente com $8,4 \mathrm{~mL}$ de água destilada e autoclavado por $45 \mathrm{~min}$ a $15 \mathrm{lbs}\left(121^{\circ} \mathrm{C}\right)$. Os vials de vidro $(40 \mathrm{~mL})$ com tampas de rosca e septos de PTFE/silicone e as fibras de polidimetilsiloxano (PDMS $100 \mu \mathrm{m}$ ) e polidimetilsiloxano/divinilbenzeno (PDMS/DVB $65 \mu \mathrm{m}$ ) foram obtidas da Sigma-Aldrich ${ }^{\circledR}$ (St. Louis, USA). As placas de Petri estéril descartáveis $\left(90\right.$ x $15 \mathrm{~mm}$ ) foram adquiridas da J. Prolab ${ }^{\circledR}$ (São José dos Pinhais, Brasil). A mistura de n-alcanos saturados $\mathrm{C}_{7}-\mathrm{C}_{30}$ foi obtida da Sigma-Aldrich ${ }^{\circledR}$ (St. Louis, USA).

\section{Cultivo do fungo e extração dos COVs}

A cepa de fungo foi inoculada em placas de Petri contendo meio BDA e incubada durante 7 dias a $25^{\circ} \mathrm{C}$ para assegurar que tinha a mesma idade. Um pellet ( $6 \mathrm{~mm}$ de diâmetro) da cepa foi transferido para frascos $(40 \mathrm{~mL})$ contendo $10 \mathrm{~mL}$ de BD, BDA, Peptona ou grãos de arroz (10 g) e imediatamente selados com septos de PTFE/ silicone e tampas roscadas. Após incubação durante 7, 14 e 21 dias a $25^{\circ} \mathrm{C}$ sob condições estáticas, os frascos foram colocados em banho de etileno glicol a $60{ }^{\circ} \mathrm{C}$ e os COVs foram extraídos por $10 \mathrm{~min}$ por HS-SPME utilizando uma fibra PDMS/DVB colocada acima (cerca de $1 \mathrm{~cm}$ ) da superfície da cultura fúngica. Em seguida, a fibra foi removida e inserida na CG-EM a $250{ }^{\circ} \mathrm{C}$ durante 4 min para a dessorção dos COVs. Utilizou-se como controle (brancos) os frascos contendo apenas os meios de cultivo sem adição do fungo. Para a otimização das condições HS-SPME foi realizado um planejamento com duas variáveis quantitativas em dois níveis (temperatura: 50 e $60{ }^{\circ} \mathrm{C}$ e tempo de extração: 10 e $20 \mathrm{~min}$ ), em duplicata, e uma variável qualitativa (tipo de fibra: PDMS e PDMS/DVB). Foram realizados 24 experimentos, sendo 16 com o fungo e 8 controles. A análise estatística foi realizada utilizando-se o programa Quality Tools: Statistics in Quality Science. ${ }^{10}$

\section{Análises de CG-EM}

As análises de CG-EM foram realizadas em um cromatógrafo a gás (Shimadzu, modelo QP-2010 Ultra), equipado com detector seletivo de massas, com auto injetor (Shimadzu, modelo AOC-20i), com coluna capilar de sílica fundida RTX-5MS ${ }^{\circledR}$ (Bellefonte, USA), (5\% de dimetilsiloxisano), com dimensões $30 \mathrm{~m}$ x 0,25 $\mathrm{mm}$ x 0,25 $\mu \mathrm{m}$. A programação de temperatura do forno $\mathrm{CG}$ consistiu em $25^{\circ} \mathrm{C}$ durante 2 min (período de dessorção), $20^{\circ} \mathrm{C} / \mathrm{min}$, até $195{ }^{\circ} \mathrm{C}, 10^{\circ} \mathrm{C} \min ^{-1}$ até $220^{\circ} \mathrm{C}, 20^{\circ} \mathrm{C} \mathrm{min}{ }^{-1}$ até $280^{\circ} \mathrm{C}$. Os parâmetros instrumentais foram: temperatura do injetor de $250{ }^{\circ} \mathrm{C}$; modo de injeção split de 1:5; vazão volumétrica da fase móvel de $1,7 \mathrm{~mL} \mathrm{~min}^{-1}$; temperatura do detector de $250{ }^{\circ} \mathrm{C}$.

Os COVs produzidos por $A$. rigidiuscula sob diferentes condições foram identificados pela comparação dos espectros de massa obtidos com os de bibliotecas espectrais de massa (Adams, ${ }^{11}$ Pherobase $^{12} \mathrm{e}$ NIST $^{13}$ ), bem como dos índices de retenção calculados baseados na cromatografia gasosa com programação linear de temperatura ${ }^{14}$ com os da literatura. ${ }^{12,13}$ Os n-alcanos $\left(\mathrm{C}_{7}-\mathrm{C}_{30}\right.$, Sigma-Aldrich $\left.{ }^{\circledR}\right)$ foram utilizados como pontos de referência no cálculo dos índices de retenção linear.

\section{Análise multivariada de dados}

Os constituintes voláteis, extraídos por HS-SPME e identificados por CG-EM, foram submetidos a análises de PCA e HCA, utilizando o software livre R Project da R Foundation for Statistical Computing ${ }^{\circledR} .{ }^{10}$ Os dados analisados correspondem às médias das injeções em triplicata e o arranjo matricial foi constituído por doze linhas (número de condições de cultivo) e quarenta e quatro colunas (compostos identificados). Para o HCA utilizou-se a distância euclidiana como coeficiente de dissimilaridade e o agrupamento foi feito pelo método de associação média (Ward), com a opção de truncamento automático para definir os conglomerados e obter o dendrograma. ${ }^{15}$

\section{RESULTADOS E DISCUSSÃO}

A extração de compostos voláteis por HS-SPME produzidos pelo fungo A. rigidiuscula em diferentes condições de cultivo foi otimizada através de planejamento experimental $2^{3}$, considerando-se temperatura $\left(50\right.$ e $\left.60^{\circ} \mathrm{C}\right)$, tempo de extração ( 10 e 20 min) e tipo de fibra (PDMS e PDMS/DVB) como variáveis. Como resultado, obteve-se o maior número de COVs detectados quando o experimento foi realizado a $60{ }^{\circ} \mathrm{C}, 10 \mathrm{~min}$ e com a fibra PDMS/DVB.

Conforme mostrado no gráfico de Pareto (Figura 1), a temperatura (A) foi a variável, que isoladamente apresentou maior influência na extração de COVs, mostrando que a otimização das condições de extração de VOCs por HS-SPME é necessária. De acordo com dados da literatura, ${ }^{8,16}$ a temperatura e o tempo afetam a eficiência de extração, alterando a cinética de transferência de massa dos compostos voláteis entre as diferentes fases do sistema, bem como a termodinâmica que descreve o equilíbrio de partição dos COVs.

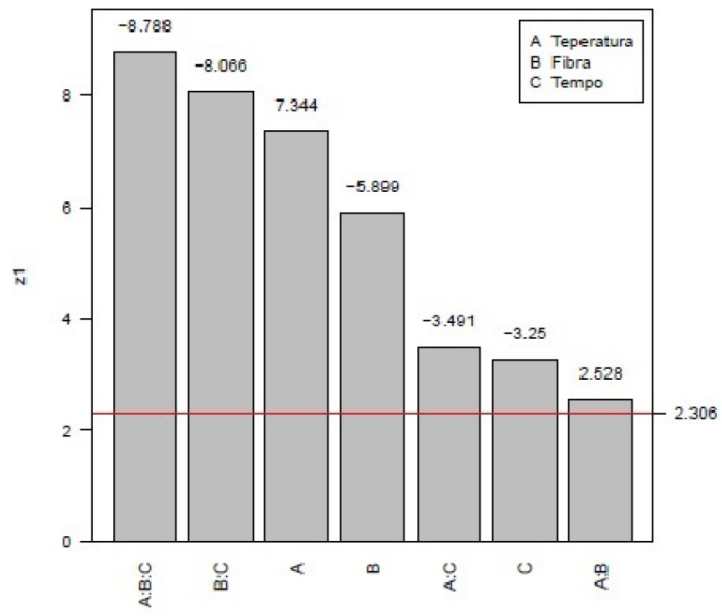

Figura 1. Gráfico de Pareto dos efeitos da temperatura (A), tipo de fibra (B) e tempo $(C)$ na extração de COVs por HS-SPME do fungo A. rigidiuscula 
Foram utilizados dois meios de cultivo líquidos, sendo um rico em carbono (BD sintético) e outro rico em carbono e nitrogênio (peptona sintético), um meio semi-sólido (BDA) e um meio sólido (arroz). Em todos os casos, $A$. rigidiuscula foi cultivado em três períodos distintos (7, 14 e 21 dias), sendo as extrações e análises de COVs realizadas no final de cada período.

A condição que apresentou a maior produção de COVs foi o cultivo de $A$. rigidiuscula em arroz durante 14 dias de incubação, sendo produzidos 32 compostos voláteis. No entanto, neste meio, houve uma diminuição na produção destes compostos com 21 dias de incubação. O cultivo de $A$. rigidiuscula em BD com 7 dias de incubação apresentou a menor produção de compostos voláteis, totalizando $7 \mathrm{COVs}$. Contudo, neste mesmo meio, houve um aumento crescente de COVs diretamente proporcional ao aumento do período de incubação, sendo observada a produção máxima de 28 COVs em 21 dias de incubação. Para os meios peptona e BDA não houve variações significativas na produção de COVs (Figura 2).

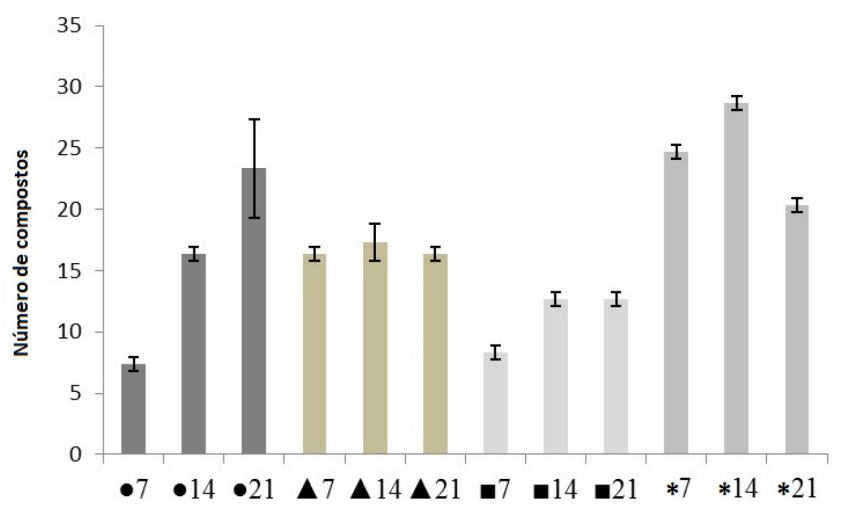

Figura 2. Produção de COVs pelo fungo A. rigidiuscula em diferentes condições: $B D(\bullet 7,14$ e 21 dias $)$, peptona $(\mathbf{\triangle}$ 7, 14 e 21 dias $), B D A(\square$ 7, 14 e 21 dias) e arroz (* 7, 14 e 21 dias), sendo $n=3$

Utilizando-se as condições otimizadas de extração por HS-SPME, após análise por CG-EM, foram identificados $44 \mathrm{COVs}$, os quais não foram observados nos cultivos controles (Tabela 1). A maioria dos compostos identificados pertence às classes dos sesquiterpenos (7 não oxigenados e 3 oxigenados) e monoterpenos (6 oxigenados). Além desses, foram identificados hidrocarbonetos de baixa massa molecular (4), hidrocarbonetos aromáticos (4), álcoois de baixa massa molecular (3), aldeídos (2), cetonas (2), ésteres de baixa e média massa molecular (5), compostos aromáticos oxigenados (5) e ésteres etílicos de ácidos graxos (3).

Os únicos compostos produzidos por A. rigidiuscula nos quatro meios de cultura e nos três períodos de incubação foram o 3-metilbutan-1-ol, 2-metilbutan-1-ol, $\gamma$-muuroleno e acetato de nerolidol. Embora em alguns casos esses compostos tenham sido detectados em pequenas quantidades, a prevalência em todas as condições credenciam este grupo de COVs como possíveis marcadores para este fungo. Dentre estes compostos, o $\gamma$-muuroleno foi o majoritário e produzido, principalmente, no meio BD com teores significativos $(40,78 \% ; 26,24 \%$ e $27,04 \%)$ para 7,14 e 21 dias de incubação, respectivamente.

Alguns compostos foram específicos para um determinado meio de cultura. O octano, acetato de 3-metilbutan-1-ol, acetato de 2-metilbutan-1-ol, octan-3-ona, eucaliptol, acetato de octan-3-ol e $\alpha$-muuroleno foram produzidos pelo fungo apenas em arroz. O composto decan-3-ona foi específico para o meio BD. Já os compostos etilbenzeno, 1,2,4-trimetilbenzeno, decanal e triacetina foram específicos para o meio de cultivo BDA. De acordo com a literatura, compostos microbianos podem ser produzidos de forma exclusiva por determinados microrganismos em condições controladas. ${ }^{9,17}$

Comparação dos compostos identificados em A. rigidiuscula com banco de dados de compostos voláteis microbianos ${ }^{18}$ revelou que apenas dezesseis deles foram anteriormente descritos como compostos voláteis de fungos (3-metilbutan-1-ol, 2-metilbutan-1-ol, octano, etilbenzeno, acetato de 3-metilbutan-1-ol, acetato de 2-metilbutan-1-ol, 1,2,4-trimetilbenzeno, feniletanol, naftaleno, decanal, $(E)$-geranilacetona, $\gamma$-muuroleno, $\beta$-selineno, valenceno, epizonareno, $\alpha$-muuroleno). Compostos como borneol, 2-metilisoborneol, decan-3-ona, isoborneol, 4-etilguaiacol, decanoato de etila e $\beta$-cariofileno foram relatados como COVs de origem bacteriana. Já a maior parte dos compostos identificados $(21$, ca. $48 \%)$ estão sendo relatados pela primeira vez como COVs fúngicos.

A análise de componentes principais (PCA) e a análise de agrupamento hierárquico (HCA), utilizando o programa $\mathrm{R},{ }^{10}$ foram empregadas como técnicas estatísticas multivariadas para explicar as diferenças entre conjuntos das doze amostras (condições de cultivo), sendo quatro meios de cultivo e três períodos de incubação do fungo A. rigidiuscula. Os dados submetidos à analise multivariada correspondem aos resultados cromatográficos (CG-EM) da média calculada das injeções em triplicata dos VOCs extraídos por HS-SPME. Para analisar e comparar os perfis de voláteis, todos os compostos identificados foram considerados.

De acordo com a análise de PCA (Figura 3), a partir dos perfis de voláteis foi possível distinguir quase todas as condições de cultivo, que explica em dois componentes principais $42,27 \%$ da variância total. A PCA só se mostrou ambígua na discriminação dos perfis voláteis do fungo cultivado em BD e BDA no período de sete dias. O dendrograma da análise de HCA (Figura 4) permite identificar um padrão de similaridade nos perfís de voláteis, conforme o meio de cultivo. Contudo, para os meios BD e BDA em sete dias de incubação essa distinção não se mostra satisfatória.

\section{CONCLUSÃO}

O perfil de compostos orgânicos voláteis de uma cepa do fungo A. rigidiuscula, em diferentes meios de cultivo e em diferentes períodos de incubação, foi investigada pela primeira vez, e quarenta e quatro compostos foram identificados. A utilização da PCA e HCA permitiu a discriminação dos perfis químicos de voláteis de acordo com o meio de cultivo, principalmente para os meios Batata-Dextrose e Arroz. A maior produção de COVs ocorreu no meio sólido Arroz com 14 dias de incubação. Alguns compostos foram identificados em todas as condições de cultivo. Dentre estes, o $\gamma$-muuroleno, que é produzido majoritariamente no meio BD e apresenta potencial para ser utilizado como marcador químico volátil para o fungo $A$. rigidiuscula.

\section{MATERIAL SUPLEMENTAR}

Figuras 1S-50S com espectros de massa dos COVs obtidos por CG-EM estão disponíveis em http://quimicanova.sbq.org.br, em arquivo pdf, com livre acesso.

\section{AGRADECIMENTOS}

Os autores agradecem às agências brasileiras CNPq (484130/20129 e 405001/2013-4) e FUNCAP (004.01.00/10) pelo apoio financeiro, à Profa. Dra. Terezinha F. de Oliveira (Faculdade de Estatística, UFPA) pelas discussões da análise multivariada e à CAPES pela bolsa de Francisco C. de Oliveira. 


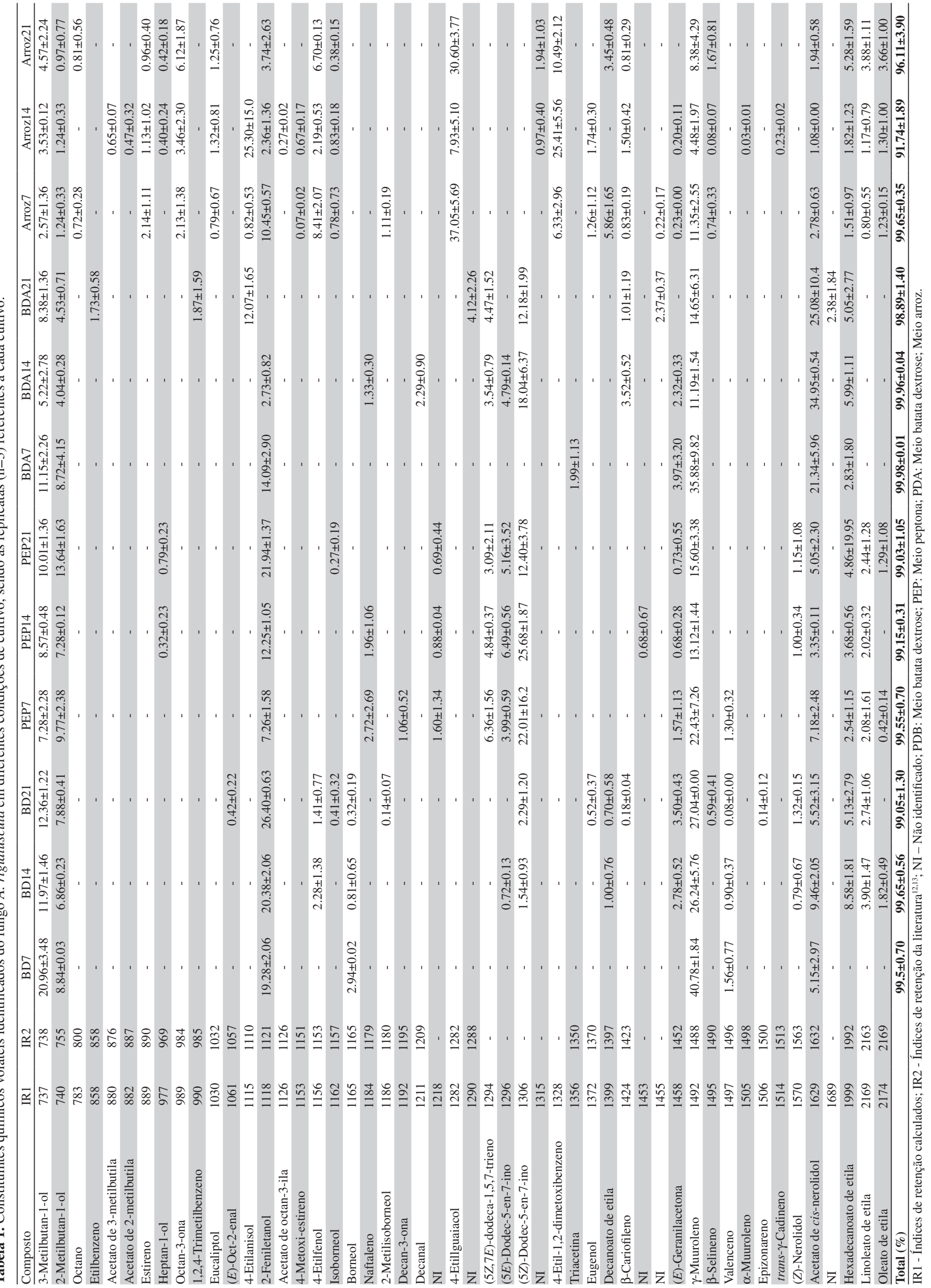




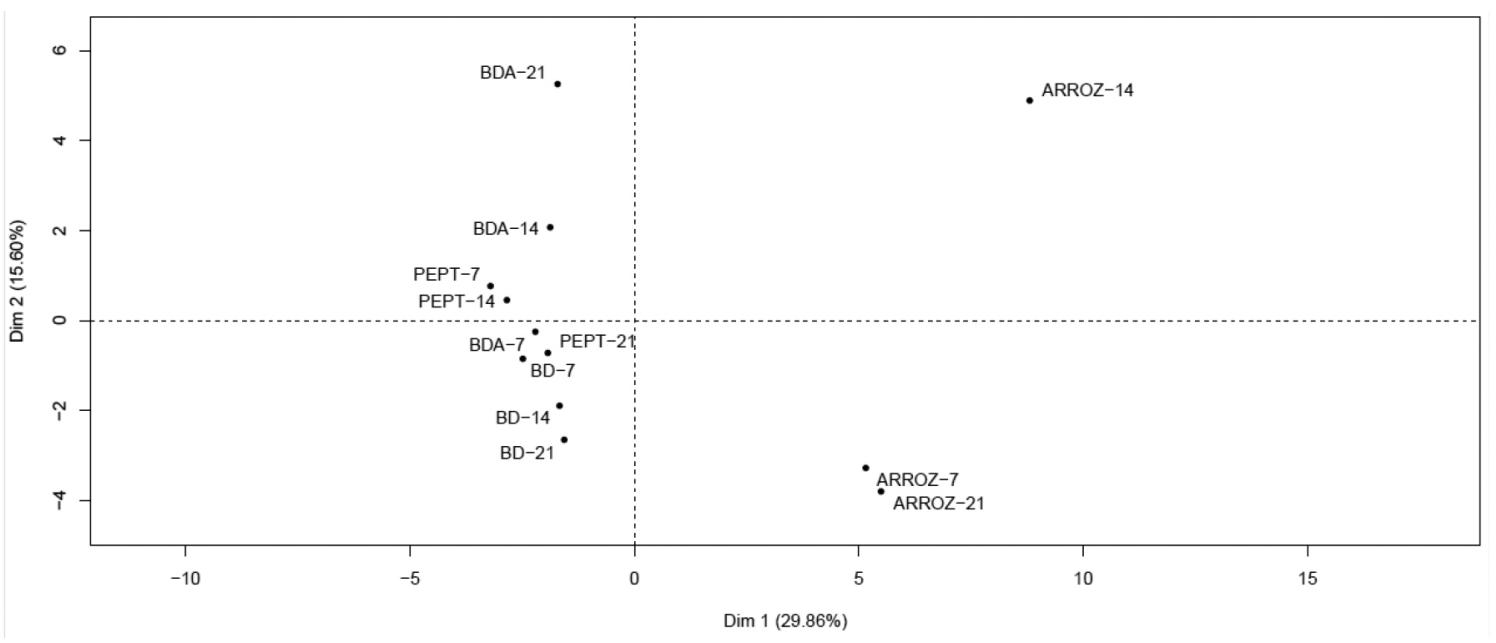

Figura 3. PCA dos escores de 44 variáveis de doze amostras obtidas por HS-SPME e CG-EM do fungo A. rigidiuscula em diferentes condições de cultivo

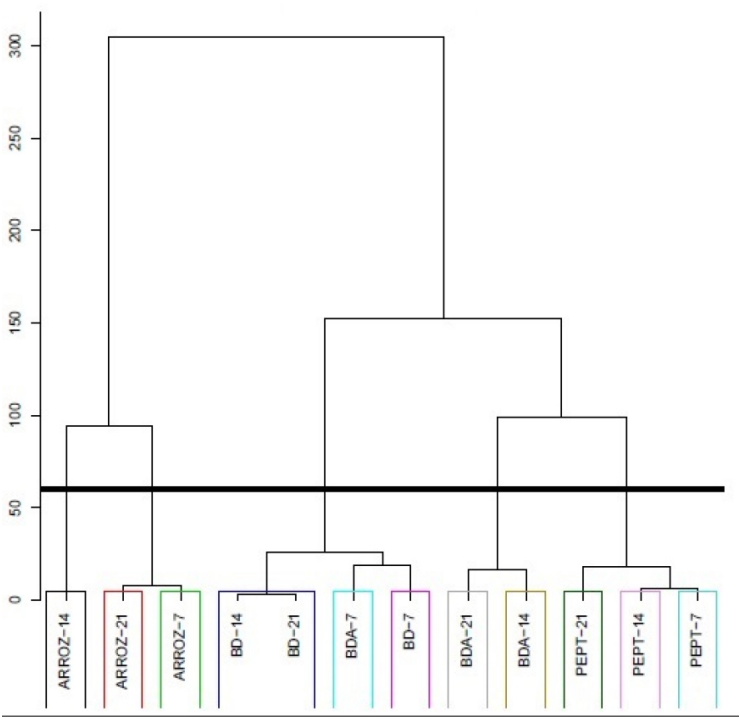

Figura 4. Dendrograma de HCA de doze amostras obtidas por HS-SPME $e$ $C G$-EM do fungo A. rigidiuscula em diferentes condições de cultivo

\section{REFERÊNCIAS}

1. Rossman, A. Y.; Samuels, G. J.; Rogerson, C. T.; Lowen, R.; Stud. Mycol. 1999, 42, 105.

2. Nong, Y.; Zhuang, W. Y.; Fungal Divers. 2005, 19, 95.

3. Li, J.; Liu, S.; Niu, S.; Zhuang, W.; Che, Y.; J. Nat. Prod. 2009, 72, 2184.

4. Lombard, L.; Bogale, M.; Montenegro, F.; Wingfield, B. D.; Wingfield, M. J.; Fungal Divers. 2008, 31, 73.
5. Junqueira, N. T. V.; Santiago, D. V. R.; Pinto, A. C. Q.; Chaves, R. C.; Embrapa Cerrados 2001, 16, 21.

6. Qi, Y. X.; Pu, J. J.; Zhang, X.; Zhang, H.; Lu, Y.; Yu, Q. F.; Zhang, H. Q.; Xie, Y. X.; J. Phytopathol. 2013, 161, 735.

7. Medentsev, A. G.; Arinbasarova, A. Yu.; Akimenko, V. K.; Appl. Biochem. Microbiol. 2005, 41, 503.

8. Oliveira, F. C.; Barbosa, F. G.; Mafezoli, J.; Oliveira, M. C. F.; Camelo, A. L. M.; Longhinotti, E.; Lima, A. C. A.; Câmara, M. P. S.; Gonçalves, F. J. T.; Freire, F. C. O.; J. Braz. Chem. Soc. 2015, 26, 2189.

9. Bago, B.; Pfeffer, P. E.; Douds, D. D.; Brouillette, J.; Bécard, G.; Shachar-Hill, Y.; Plant Physiol. 1999, 121, 263.

10. R Development Core Team (2014); R: A language and environment for statistical computing; R Foundation for Statistical Computing, Vienna, Austria, available at http://www.R-project.org.

11. Adams, R. P.; Identification of Essential Oil Components by Gas Chromatography/Mass Spectrometry, $4^{\text {th }}$ ed., Carol Stream: Illinois, 2007.

12. http://www.pherobase.com/database/compound/compounds-index. php?isvalid=yes, accessed in May 2017.

13. http://webbook.nist.gov/chemistry/, accessed in May 2017.

14. Van den Dool, H.; Kratz, P.D.; J. Chromatogr. 1963, 11, 463.

15. Hair Jr, J. F.; Anderson, R. E.; Tatham, R. L.; Black, W. C. Análise Multivariada de Dados. 5 ed., Bookman: Porto Alegre, 2005.

16. Valente, A. L. P.; Augustos, F.; Quim. Nova 2000, 23, 523; Dórea, H. S.; Gaujac, A.; Navickiene, S.; Scientia Plena 2008, 4, 1.

17. Polizzi, V.; Adams, A.; Malysheva, S. V.; Saeger, S.; Peteghem, C. V.; Moretti, A.; Picco, A. M.; Kimpe, N. Sci Total Environ. 2012, 414, 277.

18. Lemfack, M. C.; Nickel, J.; Dunkel, M.; Preissner, R.; Piechulla, B.; Nucleic Acids Res. 2014, 42, 744. 